\title{
Risk factors of maternity blues after caesarean section in Yaoundé, Cameroon: a case-control analysis
}

\author{
Pascal Foumane ${ }^{1}$, Jean Pierre Kamga Olen ${ }^{2}$, Jeanne Hortense Fouedjio ${ }^{1}$, \\ Georges Pius Kamsu Moyo ${ }^{1}$, Christiane Nsahlai ${ }^{1}$, Emile Mboudou ${ }^{1}$
}

\begin{abstract}
${ }^{1}$ Department of Obstetrics and Gynecology, Faculty of Medicine and Biomedical Sciences (FMBS), The University of Yaoundé 1, Cameroon

${ }^{2}$ Department of Internal Medicine, Faculty of Medicine and Biomedical Sciences (FMBS), The University of Yaoundé 1 , Cameroon
\end{abstract}

Received: 10 October 2016

Revised: 12 October 2016

Accepted: 03 November 2016

\section{*Correspondence:}

Dr. Pascal Foumane,

E-mail: pfoumane2004@yahoo.fr

Copyright: (C) the author(s), publisher and licensee Medip Academy. This is an open-access article distributed under the terms of the Creative Commons Attribution Non-Commercial License, which permits unrestricted non-commercial use, distribution, and reproduction in any medium, provided the original work is properly cited.

\section{ABSTRACT}

Background: Maternity blues is the most precocious and common mental derangement of the puerperium. Our objective was to identify its risk factors in women delivered by cesarean section.

Methods: This was a case-control study carried out from January 10th to April 10th 2015 in two referral hospitals of Yaoundé, Cameroon, involving 321 women delivered by cesarean section, 107 of which presented maternity blues.

Results: After multivariate analysis, independent risk factors for maternity blues after cesarean section were: low socio-economic level $(\mathrm{OR}=3.62 ; \mathrm{CI}=1.35-9.70)$, personal history of depression $(\mathrm{OR}=4.36 ; \mathrm{CI}=1.13-16.81)$, difficulties caring for the baby $(\mathrm{OR}=3.40 ; \mathrm{CI}=1.12-10.27)$ and having felt depressed or anxious during pregnancy $(\mathrm{OR}=6.61 ; \mathrm{CI}=3.05-14.31)$.

Conclusions: Women with identifiable risk factors for maternity blues should be followed up closely after cesarean deliveries.

Keywords: Cameroon, Depression, Maternity blues, Postpartum, Risk factors

\section{INTRODUCTION}

Maternity blues occurs in $50 \%$ of women during the postpartum, a period of emotional and psychological upset in a woman's life. ${ }^{1-4,6}$ This is a well-documented risk factor for postpartum depression. It has been shown that maternity blues multiply by 5 the risk of developing postpartum depression and an abnormal maternity blues scale has been reported to be a strong predictor of postpartum depression. ${ }^{5,8,10,12}$ To date and according to the literature available, maternity blues is sparsely reported in sub-Saharan Africa. The objective of this study was therefore to identify the risk factors of maternity blues in a sub-Sahara African setting.

\section{METHODS}

This was a case-control study involving 321 women who underwent a cesarean delivery, among which 107 presented maternity blues within the first ten postoperative days (case group) and 214 who did not (control group). The study was carried out from January $10^{\text {th }}$ to April $10^{\text {th }} 2015$ in two referral hospitals of Yaoundé, Cameroon. The hospitals where the patients were enrolled included the Yaoundé Gynaeco-Obstetric and Pediatric Hospital and the Yaoundé Central Hospital. After approval of the protocol by the ethical committee, women who delivered by cesarean section at 28 weeks or more of pregnancy were recruited. Each woman was counseled about the study and her consent was obtained prior to recruitment. A pretested questionnaire was 
administered by an investigator and information was retrieved from the patients' files. Data collected included: socio-demographic characteristics, obstetrical history, personal and family history, couple relationship, social support, stressful environmental factors, conception context, course of the pregnancy, new-born parameters and the Kennerley and Gath maternity blues questionnaire. The Kennerley and Gath blues questionnaire is a validated self rating scale consisting of 28 items concerning the emotional state of a newly delivered woman. The available answers are "yes" or "no" corresponding respectively to the marks of 1 and 0 , with a maximum possible score of 28 and a minimum of 0 . This score served as a diagnostic and explorative tool. Women who had an overall score greater than the mean peak score of the sample were considered positive for the condition. ${ }^{5}$

The calculated minimal sample size was 41 cases for 82 controls based on the $31.3 \%$ maternity blues rate among Nigerian postpartum women reported by Adewuya and using the formula proposed by Schlesselman, with a standardized power of $84 \%$. Statistical analyses were done using CSPro version 4.1 and SPSS version 22.0 software. ${ }^{1,7}$ The difference was statistically significant for P-value $<0.05$. The Pearson's Chi square and the Fisher's exact test were used to compare proportions. Odds ratio (OR) and its 95\% Confidence Interval (CI) were calculated to assess the association between the variables and maternity blues. Multivariate analysis was performed to identify independent risk factors.

\section{RESULTS}

One hundred and seven women who experienced maternity blues (case group) according to Kennerley and Gath score were recruited and compared to 214 women without maternity blues (control group).

The most common symptoms in women affected with maternity blues after caesarean section were (Table 1): being tearful $(91 / 107 ; 85.0 \%)$, mood swings (89/107; $83.2 \%)$, changeable in mood $(84 / 107 ; 78.5 \%)$, being mentally tense $(70 / 107 ; 65.4 \%)$, feeling depressed $(69 / 107 ; 64.5 \%)$ or anxious $(65 / 107 ; 60.7 \%)$.

A comparison of the variables between the two groups at bivariate analysis found 45 significant variables (Table 1) related to low socio-economic level, poor relationship in the couple, poor social support system (partner, family or friends), personal history of psychiatric illness or chronic disease, family history of psychiatric illness, the course of pregnancy (unplanned, depression, anxiety or physical illness) and parameters linked to the newborn health or wellbeing.

Independent risk factors of maternity blues after cesarean section following multivariate analysis were (table 3): low socio-economic level $(\mathrm{OR}=3.62 ; \mathrm{CI}=1.35-9.70)$, personal history of depression $(\mathrm{OR}=4.36$; $\mathrm{CI}=1.13$ -
16.81), having difficulties caring for the baby $(\mathrm{OR}=3.40$; $\mathrm{CI}=1.12-10.27)$ and having felt depressed or anxious during pregnancy $(\mathrm{OR}=6.61 ; \mathrm{CI}=3.05-14.31)$.

Table 1: Clinical characteristics of maternity blues in the case group $(n=107)$.

\begin{tabular}{|ll|}
\hline Symptoms & n $(\%)$ \\
\hline Tearful & $91(85.0)$ \\
\hline Mood swings & $89(83.2)$ \\
\hline Changeable in mood & $84(78.5)$ \\
\hline Mentally tense & $70(65.4)$ \\
\hline Feeling depressed & $69(64.5)$ \\
\hline Anxious & $65(60.7)$ \\
\hline Overemotional & $60(56.1)$ \\
\hline Low spirited & $51(47.7)$ \\
\hline Crying, unable to stop & $46(43.3)$ \\
\hline Concentrating poorly & $45(42.1)$ \\
\hline Oversentive & $42(39.3)$ \\
\hline Tired & $41(38.3)$ \\
\hline Helpless & $41(38.3)$ \\
\hline Emotionally reserved & $38(35.5)$ \\
\hline Happy & $37(34.6)$ \\
\hline Brooding & $34(31.8)$ \\
\hline Forgetful/muddled thinking & $33(30.8)$ \\
\hline Confident & $33(30.8)$ \\
\hline Lively & $33(30.8)$ \\
\hline Socially withdrawn & $32(29.9)$ \\
\hline Self -pitying & $31(29.0)$ \\
\hline Alert & $31(29.0)$ \\
\hline Restless & $30(28.0)$ \\
\hline Calm, tranquil & $26(24.3)$ \\
\hline Mentally relaxed & $25(23.4)$ \\
\hline Elated & $21(19.6)$ \\
\hline Irritable & $18(16.8)$ \\
\hline Emotionally numb, without feelings & $16(15.0)$ \\
\hline
\end{tabular}

\section{DISCUSSION}

Low socio-economic level is identified as an independent risk factor for maternity blues in this study. Although an association was not found between socio-economic level and maternity blues in Poland or Nigeria, Masmoudi et al. have identified low socio-economic level as a risk factor for maternity blues as well as post-partum depression in Tunisian women. ${ }^{7,9,13}$ In fact, low socioeconomic level could influence social support and care of the baby, which are known risk factors for sad mood in the postpartum period. ${ }^{9,13}$

A personal history of depression is also significantly and independently associated with maternity blues after cesarean section. This is a commonly reported finding, as physiological hormone variations following parturition are known to imbalance previous fixed psychiatric conditions. $3,9,11$ 
Table 2: Significant variables found between the group with maternity blues $(n=107)$ and the group without maternity blues $(\mathrm{n}=\mathbf{2 1 4})$ at bivariate analysis.

\begin{tabular}{|c|c|c|c|c|}
\hline Variables & $\begin{array}{l}\text { Cases } \\
\text { n }(\%)\end{array}$ & $\begin{array}{l}\text { Controls } \\
\text { n (\%) }\end{array}$ & $\begin{array}{l}\text { Odds ratio } \\
\text { (95\% CI*) }\end{array}$ & $\mathbf{P}$ \\
\hline Low socio-economic level & 37 (34.6) & $49(22.9)$ & $1.78[1.04-3.05]$ & 0,026 \\
\hline \multicolumn{5}{|l|}{ The couple relationship } \\
\hline No satisfaction & $45(42.1)$ & $43(20.1)$ & $2.88[1.7-4.9]$ & $<0.001$ \\
\hline Trouble or conflict & $36(33.6)$ & $34(15.9$ & $2,68[1.56-4.62]$ & $<0.001$ \\
\hline Having problems & $41(38.3)$ & $30(14.0)$ & $3.81[2.2-6.59]$ & $<0.001$ \\
\hline \multicolumn{5}{|l|}{ The partner } \\
\hline No adequate emotional support & $33(30.8)$ & $25(11.7)$ & $3.37[1.88-5.87]$ & $<0.001$ \\
\hline No adequate financial support & $34(31,8)$ & $23(10,7)$ & $3.87[2.16-6.9]$ & $<0.001$ \\
\hline Can't trust the partner & $36(33.6)$ & $26(12.1)$ & $3.6[2.03-6.33]$ & $<0.001$ \\
\hline \multicolumn{5}{|l|}{ The family } \\
\hline No adequate emotional support & $16(15.0)$ & $3(1.4)$ & $12.3[2.5-42.5]$ & $<0.001$ \\
\hline No adequate financial support & $43(40.2)$ & $56(26.2)$ & $1.9[1.15-3.13]$ & 0.010 \\
\hline Conflicts in the family & $19(17.8)$ & $8(3.7)$ & $5.56[2.35-13.18]$ & $<0,001$ \\
\hline Can't trust the family & $13(12.1)$ & $7(3.27)$ & $4[1.56-10.49]$ & 0.002 \\
\hline \multicolumn{5}{|l|}{ Friends } \\
\hline No adequate emotional support & $28(26.2)$ & $26(12.1)$ & $2.5[1.4-4.6]$ & 0.002 \\
\hline No adequate financial support & $59(55.1)$ & $82(38.3)$ & $1.98[1.24-3.14]$ & 0.004 \\
\hline Recent conflicts with friends & $9(8.4)$ & $7(3.3)$ & $2.72[0.98-7.51]$ & 0.046 \\
\hline Can't trust friends & $62(57.9)$ & $77(36.0)$ & $2.45[1.52-3.9]$ & $<0.001$ \\
\hline \multicolumn{5}{|l|}{ Personal history of } \\
\hline Depression & $20(18.7)$ & $7(3.3)$ & $6.8[2.72-16.97]$ & $<0.001$ \\
\hline Maternity blues & 37 (34.6) & $40(18.7)$ & $2.3[1.36-3.89]$ & 0.002 \\
\hline Other psychiatric illness & $77(72.0$ & $43(20.1)$ & $10.21[5.06-17.49]$ & $<0.001$ \\
\hline Chronic disease & $12(11.2)$ & $11(5.1)$ & $2.33[0.99-5.47]$ & 0.047 \\
\hline \multicolumn{5}{|l|}{ Family history of } \\
\hline Depression & $24(22.4)$ & $16(7.5)$ & $3.58[1.81-7.08]$ & $<0.001$ \\
\hline Other psychiatric illness & $28(26.2)$ & $16(7.5)$ & $4.39[2.25-8.55]$ & $<0.001$ \\
\hline \multicolumn{5}{|l|}{ Pregnancy course } \\
\hline Unplanned pregnancy & $56(52.3)$ & $82(38.3)$ & $1.77[1.1-2.8]$ & 0.017 \\
\hline Undesired pregnancy & $23(21.5)$ & $14(6.5)$ & $3.9[1.36-0.7]$ & $<0.001$ \\
\hline Depression or anxiety & $37(34.6)$ & $168(78.5)$ & $0.14[0.09-0.24]$ & $<0.001$ \\
\hline Complication or sickness & $14(13.1)$ & $12(5.6)$ & $2.53[1.13-5.69]$ & 0.021 \\
\hline \multicolumn{5}{|l|}{ Newborn's parameters } \\
\hline Female sex & $63(58.9)$ & $99(46.3)$ & $1.66[1.04-2.66]$ & 0.033 \\
\hline Health problems with the baby & $33(30.8)$ & $20(9.3)$ & $4.33[2.33-8.01]$ & $<0.001$ \\
\hline No baby afterbirth cry & $33(30.8)$ & $30(14.0)$ & $2.7[0.12-0.43]$ & $<0.001$ \\
\hline Resuscitation of the baby & $33(30.8)$ & $33(15.4)$ & $2.45[1.41-4.25]$ & 0.001 \\
\hline Difficulties caring for & $12(11.2$ & $11(5.1)$ & $7.65[3,15-18,59]$ & $<0.001$ \\
\hline Difficulties with baby's sleep & $32(29.9)$ & $10(4.7)$ & $8.7[4.08-18.57]$ & $<0.001$ \\
\hline Difficulties feeding the baby & $72(67.3)$ & $35(16.4)$ & $10.52[6.12-18.1]$ & $<0.001$ \\
\hline Baby irritable & $39(36.4)$ & $10(4.7)$ & $11.70[5.54-24.69]$ & $<0.001$ \\
\hline Baby crying a lot & $43(40.2)$ & $14(13.1)$ & $9.60[4.93-18.67]$ & $<0.001$ \\
\hline No breastfeeding & $67(62.6)$ & $34(15.9)$ & $8.87[5.16-15.15]$ & $<0.001$ \\
\hline
\end{tabular}

Difficulties caring for the baby are found in this study to be a risk factor of maternity blues after operative delivery. Although this finding is not commonly reported in the available literature, impaired newborn health or wellbeing is a well-documented risk factor for post- partum sad mood and depression through induced anxiety. $^{12,13}$

Having felt depressed or anxious during pregnancy is another independent risk factor for maternity blues 
identified in this series of post-cesarean women. RomeroGutiérrez et al. have found a strong association between maternal sadness and history of depressive episodes in Mexico, while Adewuya reported in Nigeria that the risk of maternity blues was multiplied by three in the presence of mood change during pregnancy.,11

Table 3: Independent risk factors of maternity blues found after multivariate analysis.

\begin{tabular}{|llll|}
\hline Variable & $\begin{array}{l}\text { Adjusted } \\
\text { odds } \\
\text { ratio }\end{array}$ & 95\% CI* & P \\
\hline $\begin{array}{l}\text { Low socio- } \\
\text { economic level }\end{array}$ & 3.62 & $1.35-9.70$ & 0.010 \\
\hline $\begin{array}{l}\text { Personal history } \\
\text { of depression }\end{array}$ & 4.36 & $1.13-16.81$ & 0.033 \\
\hline $\begin{array}{l}\text { Difficulties } \\
\text { caring for the } \\
\text { baby }\end{array}$ & 3.40 & $1.12-10.27$ & 0.030 \\
\hline $\begin{array}{l}\text { Having felt } \\
\text { depressed or } \\
\text { anxious during } \\
\text { pregnancy }\end{array}$ & 6.61 & $3.05-14.31$ & 0.000 \\
\hline $\begin{array}{l}* \text { CI }= \\
\text { Confidence }\end{array}$ & & & \\
Interval & & & \\
\hline
\end{tabular}

However, our results must be considered with some limitations considering women could have given wrong answers to our questions. This might have given some bias to our results.

\section{CONCLUSION}

Low socio-economic level, personal history of depression, difficulties caring for the baby and having felt depressed or anxious during pregnancy are independent risk factors of maternity blues after cesarean section in this study.

Women with identifiable risk factors for maternity blues should be followed up closely after cesarean section.

\section{ACKNOWLEDGEMENTS}

We acknowledge the authorities of the Yaounde GynecoObstetric and Pediatric Hospital and the Yaoundé Central Hospital who gave us permission to carry out the study at their institutions.
Funding: No funding sources

Conflict of interest: None declared

Ethical approval: The study was approved by the Institutional Ethics Committee

\section{REFERENCES}

1. Schlesselman J. Sample size requirements in casecontrol studies of disease. Am J Epidemiol. 1974;99(6): 381-4.

2. Oates M. Major mental illness in pregnancy and puerperium. Baillières Clin Obstet Gynaecol. 1987;3(4):905-20.

3. Oates M. Normal emotional changes in pregnancy and the puerperium. Baillères Clin Obstet Gynaecol. 1989; 3(6):791-804.

4. Kennerley H, Gath D. Maternity blues. III. Associations with obstetric, psychological, and psychiatric factors. Br J Psychiatry. 1989;155:367-73.

5. Kennerley H, Gath D. Maternity blues. I. Detection and measurement by questionnaire. $\mathrm{Br} \mathrm{J}$ Psychiatry. 1989;155:356-62.

6. O'Hara MW, Schlechte JA, Lewis DA, Varner MW. Controlled prospective study of post-partum mood disorders: Psychological, environmental and hormonal variables. J Abnorm Psychol. 1991;100(1):63-73.

7. Adewuya AO. Prevalence and risk factors of maternity blues in western Nigerian women. Am J Ostet Gynecol. 2005;193(4):1522-5.

8. Adewuya AO. Early postpartum mood as a risk factor for postnatal depression in Nigerian women. Am J Psychiatry. 2006;163(8):1435-7.

9. Kosińska-Kaczyńska K, Horosz E, Wielgoś M, Szymusik I. Affective disorders in the first week after the delivery: prevalence and risk factors. Ginekol Pol. 2008;79(3):182-5.

10. Piacentini D, Leveni D, Primerano G, Cattaneo M, Volpi L, Biffi G, Mirabella F. Prevalence and risk factors of postnatal depression among women attending antenatal courses. Epidemiol Psichiatr Soc. 2009;18(3):214-20.

11. Romero-Gutiérrez G, Dueñas-de la Rosa EM, Regalado-Cedillo CA, Ponce-Ponce de León AL. Prevalence of maternal sadness and its associated factors. Ginecol Obstet Mex. 2010;78(1):53-7.

12. Youn JH, Jeong IS. Predictors of postpartum depression: prospective cohort study. J Korean Acad Nurs. 2013;43(2):225-35.

13. Masmoudi J, Charfeddine F, Trabelsi S, Feki I, Ben Ayad B, Guermazi M, et al. Postpartum depression: prevalence and risk factors. A prospective Study concerning 302 Tunisian parturients. Tunis Med. 2014;92(10):615-21.

Cite this article as: Foumane $\mathrm{P}$, Kamga Olen JP, Fouedjio JH, Kamsu Moyo GP, Nsahlai C, Mboudou E. Risk factors of maternity blues after caesarean section in Yaoundé, Cameroon: a case-control analysis. Int J Reprod Contracept Obstet Gynecol 2016;5:4424-7. 